\title{
PENGARUH BENTUK MERCU BENDUNG TERHADAP TINGGI LONCAT AIR KOLAM OLAK MODEL USBR IV (SIMULASI LABORATORIUM)
}

\author{
M. Kabir Ihsan \\ Jurusan Teknik Sipil, Fakultas Teknik, Universitas Malikussaleh \\ email: ikhsankb@gmail.com
}

\begin{abstract}
Abstrak
Kolam olak Model USBR IV adalah salah satu jenis kolam olak yang sering digunakan pada sebuah bendung. Tinggi loncat air dalam kolam olakan direncanakan untuk meredam air akibat terjunan. Perhitungan perencanaan menggunakan rumus-rumus empiris yang telah lazim, dalam hal ini dipakai metodeVen Te Chow, 1989. Untuk membuktikan rumus-rumus tersebut dicoba melakukan simulasi laboratorium dalam beberapa model, debit yang berbeda, kemiringan yang berbeda. simulasi menggunakan flume yaitu satu set model saluran terbuka dengan dinding tembus pandang yang diletakkan pada struktur rangka kaku, dasar saluran ini dapat diubah kemiringannya. Saluran ini dilengkapi pula dengan tangki pelayanan berikut dengan pompa sirkulasi air, pengukur debit, tube pitot, flow meter, mistar dan Mercu.Setelah dilakukan pengolahan data dan perhitungan maka di peroleh hasil besarnya debit, kemiringan dasar saluran dan perbedaan bentuk mercu mempengaruh tinggi loncat air. Semakin besar debit yang dipakai maka semakin tinggi pula loncat air yang dihasilkannya.Tinggi loncat air pada mercu bulat lebih tinggi dari pada tinggi loncat air pada mercu ambang lebar.Pada perbandingan tinggi loncat air diatas kolam olak pada mercu ambang lebar lebih tinggi dari pada mercu bulat pada debit dan kemiringan yang sama.
\end{abstract}

Kata kunci: Loncat air, Kolam olakan, Mercu

\section{Pendahuluan}

Dalam bidang hidroteknik terdapat permasalahan tentang loncat air pada sebuah bendungan yang dapat diselesaikan dengan cara analisis namun perlu dilakukan pengamatan secara langsung terhadap analisis tersebut yang kemudian akan dilakukan pengamatan untuk melihat keadaan yang terjadi sebenarnya dilaboratorium. Bangunan bendung dimaksudkan yaitu untuk meninggikan muka air sungai agar dapat disadap.Tujuan selebihnya adalah dengan naiknya muka air sehingga akan dapat digunakan untuk mengaliri sawah. Ada dua tipe bendung yang lazim dibuat di Indonesia adalah bendung dengan tipe mercu ambang lebar dan bendung tipe mercu bulat. Sedangkan Loncat air merupakan kejadian pelepasan pada suatu aliran yang terjadi apabila suatu aliran superkritis berubah menjadi aliran subkritis. Sedangkan bentuk mercu mempengaruhi tinggi loncat air dan mempengaruhi gerusan yang terjadi pada kolam olakkan.Salah satu cara yang bisa dipakai untuk mengetahui pengaruh bentuk mercu terhadap tinggi loncat air dengan di lakukanpengamatan di laboratorium.Denganmelakukan pengamatan pada suatu bentuk mercu dapat dilihat secara langsung pengaruh yang terjadi pada loncat air.

Bertitik tolak dari latar belakang yang telah diuraikan di atas, maka masalah penelitian ini dapat dirumuskan sebagai berikut: apakah dengan bentuk mercu yang berbeda menggunakan model USBR IV dapat mempengaruhi tinggi loncat air.

Pengaruh Bentuk Mercu Bendung Terhadap Tinggi Loncat Air Kolam Olak Model USBR IV (Simulasi Laboratorium) - M. Kabir Ikhsan 
Tujuan dari penelitian ini adalah untuk melihat terjadinya tinggi loncat air yang menggunakan dua mercu yang berbeda yaitu mercu bulat dan mercu ambang lebar dengan menggunakan model kolam olak USBR IV pada variasi kemiringan dasar saluran, dan variasi debit yang berbeda. Manfaat dari penelitian ini adalah berupa masukan pengetahuan, khususnya di bidang hidraulika terapan yang berkaitan dengan karateristik loncatan dan aliran air demi efektivitas pengelolaan pelayanan air melalui saluran dan bangunan-bangunan hidraulik lainnya. Pada pelaksanaan ini akan dilakukan pengamatan dilaboratorium menggunakan mercu bulat dan mercu ambang lebar kemudian dianalis perhitungan dari hasil pengamatan dilaboratorium.

\section{Tinjauan Kepustakaan}

\subsection{Bendung}

Menurut Chow, V.T (1959), Bendung adalah bangunan yang ditempatkan melintang sungai, dan berguna untuk mengatur aliran air sungai tersebut. Berdasarkan fungsinya bendung dapat diklasifikasikan dalam bendung pembanjir, bendung penahan air pasang dan bendung penyadap.Selain itu tergantung dari konstruksinya bendung dapat diklasifikasikan dalam bendung tetap dan bendung gerak.Type adalah bendung tetap dibuat melintang searah dengan sungai untuk menghasilkan elevasi air minimum agar air tersebut bisa dielakkan dan bendung gerak dapat dipergunakan untuk mengatur tinggi dan debit air sungai dengan pembukaan pintu-pintu yang terdapat pada bendung tersebut.

\subsection{Mercu}

\subsubsection{Mercu Bulat}

Dua bentuk mercu tetap yang umum digunakan sebagai bangunan pengatur muka air pada irigasi adalah bentuk mercu bulat dan ambang lebar seperti diperlihatkan pada gambar 1 .
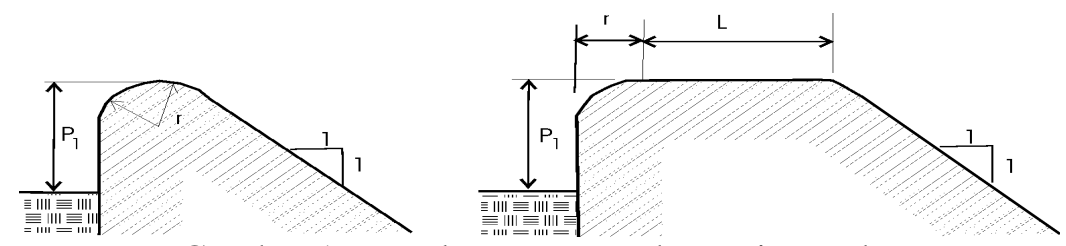

Gambar 1 Bentuk Mercu Bendung Tipe Bulat

Pada mercu tetap dengan mercu bulat (kiri) berlaku hubungan: $\mathrm{H} 1 / \mathrm{r}=5,0$ dan $\mathrm{C}_{\mathrm{d}}=1,48$. Sedangkan pada ambang lebar (kanan) berlaku hubungan: $\mathrm{H} 1 / \mathrm{L}=$ 1,0 dan $\mathrm{C}_{\mathrm{d}}=1,03$.

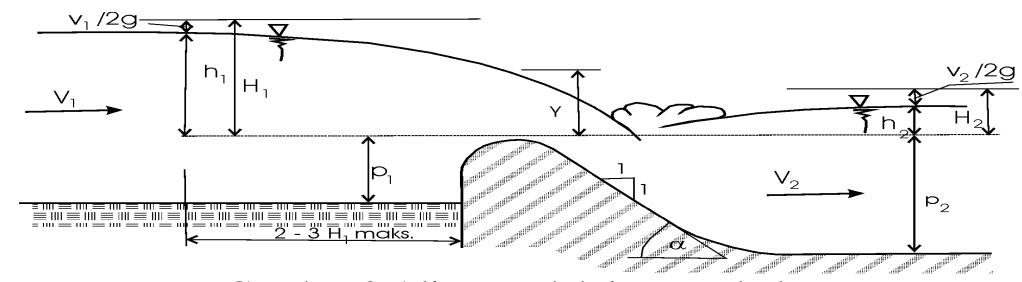

Gambar 2 Aliran melalui mercu bulat

Pengaruh Bentuk Mercu Bendung Terhadap Tinggi Loncat Air Kolam Olak Model USBR IV (Simulasi Laboratorium) - M. Kabir Ikhsan 
Rumus pengaliran:

$$
\mathrm{Q}=\mathrm{C}_{\mathrm{d}} 2 / 3 \sqrt{2 / 3 g} \mathrm{~b}_{\mathrm{c}} \mathrm{H}_{1}^{1.50}
$$

di mana :

$\mathrm{Q}=$ Debit dalam $\mathrm{m}^{3} /$ detik.

$\mathrm{C}_{\mathrm{d}}=$ koefesien debit.

$\mathrm{g}=$ percepatan $\operatorname{gravitasi}(=9.8 \mathrm{~m} /$ detik $)$

$\mathrm{b}_{\mathrm{c}}=$ Lebar mercu, meter

$\mathrm{H}_{1}=$ kedalaman air hulu terhadap ambang bangunan ukur, meter .besarnya $\mathrm{H}_{2} / \mathrm{H}_{1}$ tidak boleh melebihi 0.33 agar tidak terjadi aliran tenggelam.

\subsubsection{Mercu Ambang Lebar}

Menurut Nastain danSurosa (2005), mercu ambang lebar adalah suatu struktur bangunan air di mana garis-garis aliran bergerak secara paralel antara satu dengan yang lainnya paling sedikit pada suatu jarak yang pendek. jadi distribusi tekanan hidrostatis dianggap terjadi pada suatu tampang kendali. bendungan ukur ambang lebar ini mempunyai bentuk seperti Gambar 3

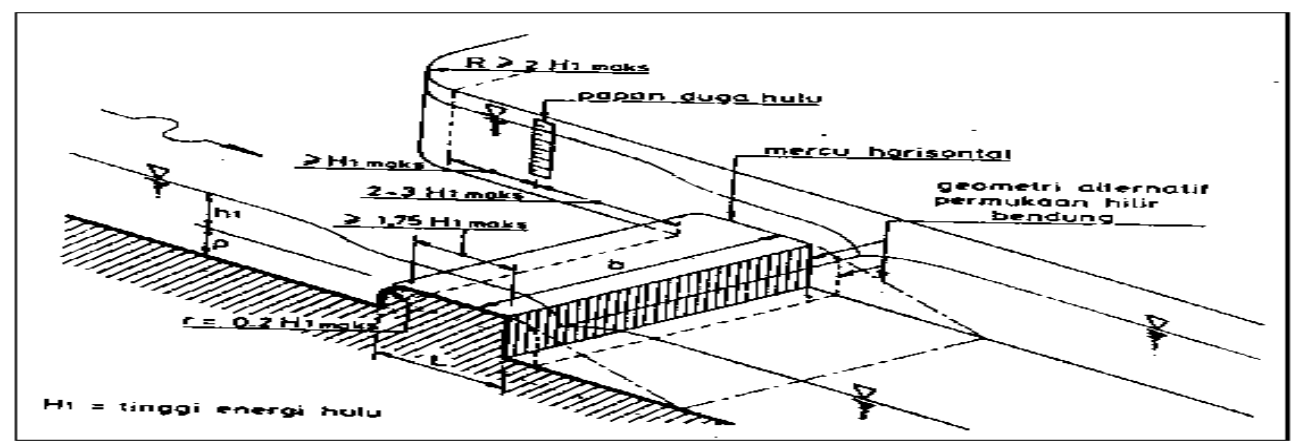

Gambar 3 Bangunan ambang lebar

Rumus pengaliran:

$$
\mathrm{Q}=\mathrm{C}_{\mathrm{d}} \mathrm{C}_{\mathrm{v}} 2 / 3 \sqrt{2 / 3 g} \mathrm{~b}_{\mathrm{c}} \mathrm{h}_{1}^{1,50}
$$

di mana :

$$
\mathrm{Q}=\text { debit dalam } \mathrm{m}^{3} / \text { detik }
$$

$\mathrm{C}_{\mathrm{d}}=$ koefesien debit

$$
=0,93+0,10 \mathrm{H}_{1} / \mathrm{L} \text { untuk } 0,1<\mathrm{H}_{1} / \mathrm{L}<1,0
$$

$\mathrm{C}_{\mathrm{v}}=$ koefesien kecepatan datang

$\mathrm{g}=$ percepatan gravitasi $\left(=9,8 \mathrm{~m} / \mathrm{dtk}^{2}\right)$

$\mathrm{b}_{\mathrm{c}}=$ lebar mercu, meter

$\mathrm{h}_{1}=$ kedalaman air hulu terhadap ambang bangunan ukur, meter

\subsection{Loncat Air}

Menurut Triatmodjo (1996), Loncat air terjadi akibat adanya perubahan aliran dari aliran superkritis menjadi aliran subkritis, di mana aliran ini terjadi pada saat bukaan pintu air berada dibawah kedalaman kritis disuatu aliran, atau pada saat air keluar dari suatu pelimpah. 
Pada percobaan loncat air dapat dilihat olakannya yang sangat besar dengan pengurangan energi yang sangat besar, sehingga loncat air menjadi tenang oleh karena kecepatannya berkurang secara mendadak dan kedalamanya bertambah secara cepat.

Loncat air dapat diaplikasikan sebagai perendam energi pada bangunan air sehingga pengikisan struktur di hilir bendung dapat dicegah, sehingga memperbesar tekanan lapisan lindung serta memperkecil tekanan angkat struktur tembok dengan memperbesar kedalaman pada lapis lindung pada kantong udara penyuplai air sehingga mencegah penguncian udara.

\subsection{Kolam Olak USBR IV}

Untuk mengatasi terjadinya kerusakan pada lantai kolam olak, maka dilakukan perendam energi. Tipe kolam olak yang ada pada model fisik mendung ini menggunakan model kolam olak USBR IV. Kolam ini dianjurkan digunakan untuk loncatan hidrolik yang nilai $F_{1}=2,5$ sampai 4,5 dan biasanya nilai nilai ini terjadi pada struktur kanal dan bendungan pengelak. Rancangan ini sangat memperkecil gelombang-gelombang yang terbentuk pada loncatan yang tidak sempurna, seperti diperlihatkan pada Gambar 4.

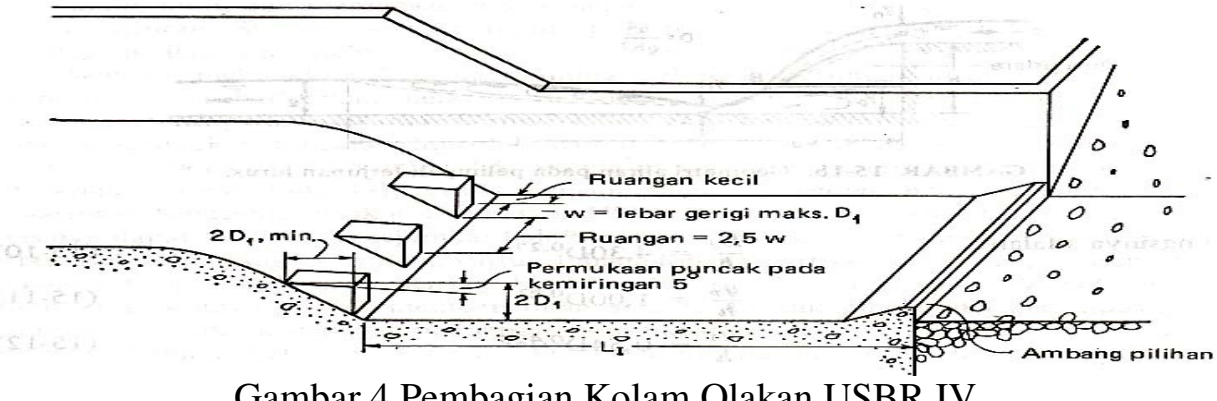

Gambar 4 Pembagian Kolam Olakan USBR IV.

Bila $F_{1}=2,5$ sampai 4,5 pada kolam olakkan akan menghasilkan loncatan hidrolik yang berosilasi, menimbulkan gelombang yang sukar diredam. Kolam USBR IV dibuat untuk mengatasi masalah dengan menghilangkan gelombang pada sumbernya.hal ini dapat dicapai dengan mengitensifkan pengulungan yang kelihatan pada bagian atas loncatan.dengan arah semburan penyimpang dari blok muka kolam olakkan yang besar. Jumlah blok muka kolam olakkan yang ditunjukkan pada gambar 2.3 adalah jumlah minimum yang dibutuhkan. Untuk mendapatkan karakteristik hidrolik yang lebih baik diperlukan blok-blok yang lebih kecil daripada yang ditunjukkan pada gamba5 4 biasanya $0,75 \mathrm{D}_{1}$ dan mengatur kedalaman air bawah 5-10\% lebih besar dari kedalaman lanjut dari loncatan.

\section{Metode Penelitian}

\subsection{Tahapan Pelaksanaan Penelitian}

Pengumpulan data penelitian tentang pengaruh bentuk mercu bendung terhadap loncat air di laboratorium. Setelah melakukan penelitian dan pengamatan di laboratorium, sehingga mendapatkan pengaruh bentuk mercu terhadap tinggi loncat air. 


\subsection{Peralatan Yang Digunakan} berikut:

Peralatan-peralatan yang digunakan pada percobaan ini adalah sebagai

a. Flume, satu set model saluran terbuka dengan dinding tembus pandang yang diletakkan pada struktur rangka kaku. Dasar saluran ini dapat diubah kemiringannya. Saluran ini dilengkapi pula dengan tangki pelayanan berikut dengan pompa sirkulasi air dan pengukur debit.

b. tube pitot

c. flow meter

d. mistar atau pita ukur;

e. Mercu bulat.

\subsection{Langkah Percobaan}

Sebelum memulai percobaan, pastikan dahulu bahwa Tangki air telah diisi air bersih; Atur flume pada posisi horizontal, dan pastikan tidak ada aksesoris lain di dalam flume; Pasang pelimpah pada posisi di mana profil airnya seragam; Untuk pengamatan loncat air, pasang floodgate pada ujung saluran; Pasang tube pitot untuk mengukur kecepatan aliran.

Dalam pelaksanaan percobaan dilakukan langkah-langkah sesuai dengan prosedur sebagai berikutnya:

a. Hidupkan pompa, atur aliran dengan kecepatan rendah sampai air dibelakang pelimpah naik.

b. Amati saat dimana air mulai meluncur dari pelimpah dan bagaimana bentuk aliran dari meluncur sampai menuju floodgate.

c. Atur aliran dan tutup floodgate perlahan-lahan sampai muncut loncat air

d. Ukur kedalaman aliran dan kecepatan aliran sebelum dan setelah loncat air

e. Secara bertahap tambahkan aliran. Perhatikan bagaimana bentuk perubahan loncat air. Untuk setiap tahapan, ukur kedalaman dan kecepatan aliran sebelum dan setelah loncat air.

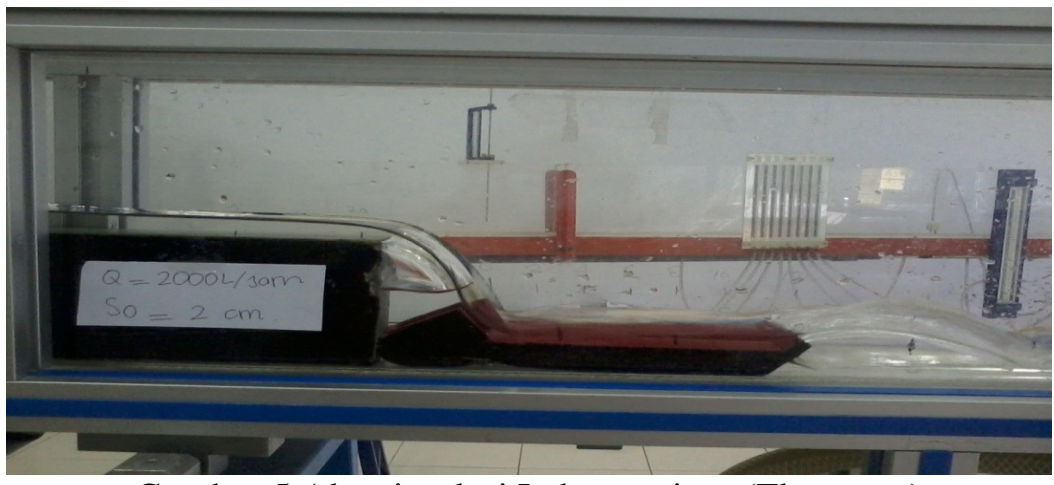

Gambar 5 Alat simulasi Laboratorium (Flume set)

Dari percobaan tersebut maka akan dilihat tinggi loncat air pada bangunan pelimpah (mercu bulat) dan ambang lebar. Loncat air akan terjadi apabila aliran superkritis dan subkritis bertemu karena aliran yang melewati floodgate dan aliran yang telah meluncur dari pelimpah dapat membentuk loncat air. 


\section{Hasil dan Pembahasan}

\subsection{Hasil}

Hasil dan pengolahan data profil tinggi loncat air pada simulasi laboratorium berupa kalibrasi alat, klasifikasi tinggi loncat air dengan menggunakan Persamaaan (2) pada mercu bulat dan persamaan (3) pada mercu ambang lebar, dari perbandingan hasil terjadi perubahan tinggi loncat air pada simulasi laboratorium dengan perhitungan dan perbandingan hasil perubahan tinggi loncat air pada mercu bulat dan mercu ambang lebar.

\subsubsection{Tinggi Loncat Air SimulasiLaboratorium.}

Dari data simulasi laboratorium diambildenganmengukurtinggi muka air di atas mercu pada masing-masing jarak $5 \mathrm{~cm}$, untuk mengukur tinggi loncat air diatas kolam olak masing-masing jarak $2 \mathrm{~cm}$, sedangkan untuk tinggi loncat air setelah kolam olak masing-masing jaraknya $5 \mathrm{~cm}$ baik dengan kemiringan dasar saluran $\left(\mathrm{S}_{0}\right) 0$ dan 0,002 dengan debit (Q) $1000 \mathrm{~L} / \mathrm{Jam}, 2000 \mathrm{~L} / \mathrm{Jam}, 3000$ L/Jamdan $4000 \mathrm{~L} / \mathrm{Jam}$ yang dianalisis pada kedua jenis bentuk bendung. Dari hasil penelitian tersebut diperoleh tinggi loncatair (y) di atas mercu bulat dengan jarak $5 \mathrm{~cm}$ dengan $\mathrm{Q}=1000 \mathrm{l} / \mathrm{jam}, \mathrm{S}_{0}=0$ adalah setinggi $1,5 \mathrm{~cm}$, pada mercu ambang lebar setinggi 2,8. Tinggi loncat air diatas kolam olakan pada mercu bulat dengan jarak $2 \mathrm{~cm}$ adalah setinggi $1,8 \mathrm{~cm}$ sedangkan pada mercu ambang lebar adalah setinggi 0,1 .

Tinggi loncat air setelah kolam olakkan pada mercu bulat adalah setinggi 1,3 $\mathrm{cm}$ sedangkan pada mercu ambang lebar adalah setinggi $3,3 \mathrm{~cm}$. panjang loncat air pada mercu bulat adalah setinggi $1,8 \mathrm{~cm}$ dan panjangnya $2 \mathrm{~cm}$ sedangkan pada mercu ambang lebar tinggi loncat air adalah $2,1 \mathrm{~cm}$ dan panjangnya $3 \mathrm{~cm}$. untuk $\mathrm{Q}=2000 \mathrm{l} / \mathrm{jam}, \mathrm{S}_{0}=0$ adalah setinggi $2,6 \mathrm{~cm}$, pada mercu ambang lebar setinggi $3 \mathrm{~cm}$.

Tinggi loncat air di atas kolam olakkan pada mercu bulat dengan jarak $2 \mathrm{~cm}$ adalah setinggi $3 \mathrm{~cm}$ sedangkan pada mercu ambang lebar adalah setinggi $4 \mathrm{~cm}$. Tinggi loncat air setelah kolam olakan pada mercu bulat adalah setinggi $4,2 \mathrm{~cm}$ sedangkan pada mercu ambang lebar adalah setinggi $3,5 \mathrm{~cm}$. panjang loncat air pada mercu bulat adalah setinggi $2 \mathrm{~cm}$ dan panjangnya $9 \mathrm{~cm}$ sedangkan pada mercu ambang lebar tinggi loncat air adalah $2,1 \mathrm{~cm}$ dan panjangnya $3 \mathrm{~cm}$. UntukQ $=3000 \mathrm{l} / \mathrm{jam}, \mathrm{S}_{0}=0$ adalah setinggi $3,4 \mathrm{~cm}$, pada mercu ambang lebar setinggi $3,7 \mathrm{~cm}$.

Tinggi loncat air diatas kolam olakkan pada mercu bulat dengan jarak $2 \mathrm{~cm}$ adalah setinggi 2,9 $\mathrm{cm}$ sedangkan pada mercu ambang lebar adalah setinggi 5,9 $\mathrm{cm}$. Tinggi loncat air setelah kolam olakan pada mercu bulat adalah setinggi 4,6 $\mathrm{cm}$ sedangkan pada mercu ambang lebar adalah setinggi $4,9 \mathrm{~cm}$. panjang loncat air pada mercu bulat adalah setinggi $1,8 \mathrm{~cm}$ dan panjangnya $2 \mathrm{~cm}$ sedangkan pada mercu ambang lebar tinggi loncat air adalah $2,1 \mathrm{~cm}$ dan panjangnya $3 \mathrm{~cm}$. Untuk $\mathrm{Q}=4000 \mathrm{~L} / \mathrm{jam}$, So $=0$ adalah setinggi 3,5 cm mercu ambang lebar 4,7 cm. tinggi loncat air diatas kolam olakpada mercu bulat dengan jarak $2 \mathrm{~cm}$ adalah setinggi $2,9 \mathrm{~cm}$ sedangkan pada mercu ambang lebar $6,2 \mathrm{~cm}$. tinggi loncat air setelah kolam olak pada mercu bulat $4,7 \mathrm{~cm}$, sedangkan pada mercu ambang lebar 4,5 $\mathrm{cm}$. panjang loncat air pada mercu bulat $1,3 \mathrm{~cm}$ dan tingginya $2 \mathrm{~cm}$, sedangkan panjang ambang lebar yaitu $12 \mathrm{~cm}$, dan tingginya $11 \mathrm{~cm}$. 


\subsubsection{Kalibrasi Alat}

Perhitungan debit control yang dilakukan sebelum mercu dipasang di hilir bendung. Debit control dilakukan pada setiap variasi debit dan kemiringan dasar saluran saat penelitian. Untuk setiap percobaan dapat dihitung debit control dengan mengetahui $\mathrm{Q}_{\mathrm{baca}}=20001 / \mathrm{jam}\left(0,00027 \mathrm{~m}^{3} / \mathrm{det}\right), \mathrm{b}=6,4 \mathrm{~cm}(0,064 \mathrm{~m}), \mathrm{y}=$ $2,4 \mathrm{~cm}(0,024 \mathrm{~m}) \operatorname{dan} \frac{V^{2}}{2 g}=0,00167 \mathrm{~m}$

\subsubsection{Klasifikasi Tinggi Loncat Air Menggunakan Rumus}

Dari hasil perhitungan dengan menggunakan rumus persamaan (2) memiliki bentuk loncat air yang tidak jauh berbeda dengan hasil simulasi laboratorium, maka distribusi menggunakan rumus dapat digunakan serta dapat dilanjutkan keperhitungan selanjutnya

\subsection{Pembahasan}

Setelah air di laboratorium dan didapat hasil, maka pembahasan meliputi hasil dari perhitungan yang telah dilakukan mencakup:

\subsubsection{Tinggi Loncat Air Simulasi Laboratorium}

Simulasi tinggi loncat air di laboratorium dilakukan dengan menggunakan alat flume meter yang terdiri dari kaca, tube pitot, flow meter dan mistar untuk mengukur ketinggian air. Sebelum dilakukan percobaan tangki air terlebih dahulu diisi dengan air bersih, kemudian flume diatur horizontal dan tidak ada asesoris apapun di dalam flume. Tahapan berikutnya diukur tinggi puncak bendung dari dasar saluran. Kemudian pompa di hidupkan lalu katup input aliran dibuka dan diatur aliran sebatas maksimum sehingga dapat melewati bendung. Saat air dalam keadaan normal di catatan pada flowmeter kemudian diukur kedalaman aliran pada bagian atas bendung, tinggi loncat air di atas kolam olak serta tinggi loncat air setelah kolam olak untuk mendapatkan dimana terjadi loncat air. Percobaan dilakukan pada empat variasi aliran, empat variasi debit dan pada dua variasi kemiringan dasar saluran dengan menggunakan langkah yang sama. Hasil pengamatan dicatat sehingga didapat ketinggian loncat air (y) pada kedua jenis mercu. Tinjauan simulasi dilaksanakan terhadap dua jenis bendung yaitu bendung tipe bulat dan bendung tipe ambangl ebar yang menggunakan kolam olak model USBR IV.Mercu ambang lebar dan mercu bulat mempunyai tebal, tinggi dan panjang yang sama yaitu dengan lebar mercu $9 \mathrm{~cm}$, tinggimercu $6 \mathrm{~cm}$, panjang mercu $22 \mathrm{~cm}$ dengan tinggi peluapan relative sesuai dengan variasi debit dan sebagainya.

\subsubsection{KalibrasiAlat}

Untuk memastikan bahwa simulasi yang dilaksanakan terkontrol, maka harus dilakukan kalibrasi alat pada setiap percobaan. Kalibrasi alat dilakukan pada tabung tube pitot untuk mengontrol debit pada keadaan normal agar debit terkontrol pada saat dilakukan simulasi. Pada saat kalibrasi alat dilakukan pada debit 1000 L/jam dengan kemiringan dasar saluran (So) 0 hasil yang didapat sama dengan debit baca pada saat dilakukan simulasi. Dengan demikian debit yang dipakai saat simulasi terkontrol. 


\subsubsection{Klasifikasi Tinggi Loncat Air Menggunakan Rumus}

Mengingat aliran adalah aliran sub kritis maka perhitungan tinggi loncat air dilakukan dari hilir ke hulu, jarak dari hilir ke hulu bendung adalah 200. Kedalaman air di titik 1 pada atas mercu ambang lebar atau $\mathrm{y}_{1}=2,8 \mathrm{~cm}$ dan kedalaman di titik 1 pada mercu bulat dengan $\mathrm{y}_{1}=1,4$ cmdengan menggunakan $\Delta \mathrm{x}$ $5 \mathrm{~cm}$. Tinggi muka di atas kolam olak di titik 1 pada atas mercu ambang lebar atau $\mathrm{y}_{1}=0,1 \mathrm{~cm}$ dan tinggi muka di atas kolam olak di titik 1 pada atas mercu bulat atau $\mathrm{y}_{1}=2,6 \mathrm{~cm}$ dengan menggunakan $\Delta \mathrm{x} 2 \mathrm{~cm}$. Tinggi loncat air setelah kolam olak di titik 1 pada mercu ambang lebar atau $\mathrm{y}_{1}=3,3$ dan tinggi loncat air setelah kolam olak di titik 1 pada mercu bulat atau $\mathrm{y}_{1}=3 \mathrm{~cm}$ dengan menggunakan $\Delta \mathrm{x} 5 \mathrm{~cm}$. kemudian dihitung kedalaman di setiap $\Delta \mathrm{x}$ seterusnya yang berjarak $\Delta \mathrm{x}_{\mathrm{i}}=\mathrm{x}_{\mathrm{i}}+\ldots \ldots . \mathrm{x}_{\mathrm{n}}$ pada kedua jenis mercu yang digunakan dengan berbagai variasi kemiringan dasar saluran, besarnya debit yang digunakan serta menggunakan kolam olakan tipe USBR IV. Dengan mengetahui koefisien debit, percepatan gravitasi dan kedalaman air hulu terhadap ambang bangunan maka besarnya debit dapat dihitung.

\subsubsection{Perbandingan Hasil Perubahan Tinggi Loncat Air Simulasi Lab dan Hasil Perhitungan.}

Untuk melihat hasil perbandingan perubahan tinggi loncat air simulasi laboratorium dengan yang menggunakan rumus, maka setelah dilakukan perhitungan hasil yang didapat disajikan dalam bentuk grafik. Dari grafik tersebut dapat dilihat secara jelas perbedaan tinggi loncat air pada kedua mercu.

Perbandingan hasil simulasi laboratorium tinggi loncat air di atas kolam olak dengan hasil perhitungan pada mercu bulat dengan variasi debit $1000 \mathrm{l} / \mathrm{jam}$ $\left(0,00027 \mathrm{~m}^{3} / \mathrm{det}\right), 20001 / \mathrm{jam}\left(0,00055 \mathrm{~m}^{3} / \mathrm{det}\right), 30001 / \mathrm{jam}\left(0,00083 \mathrm{~m}^{3} / \mathrm{det}\right) \mathrm{dan}$ debit 4000 1/jam $\left(0,0011 \mathrm{~m}^{3} /\right.$ det $)$ dan kemiringan 0 diprtlihatkan pada Gambar 6 .
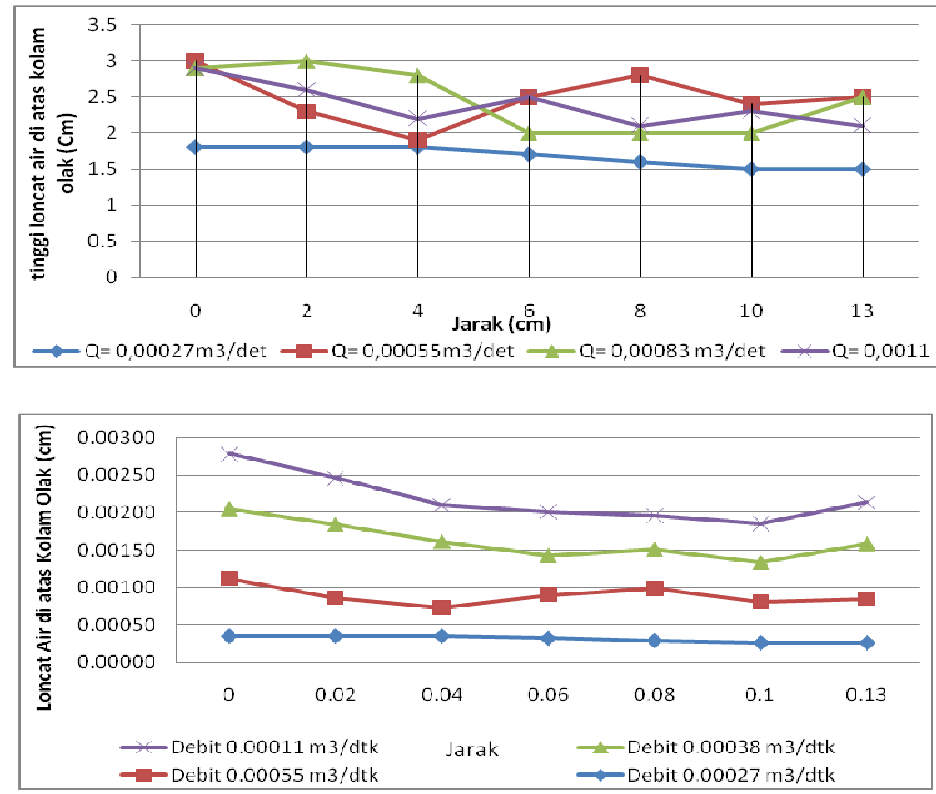

Gambar 6 Grafik simulasi laboratorium tinggi Loncat Air di atas Kolam Olak Pada Mercu Bulat, $\mathrm{S}_{0}=0$ 
Perbandingan hasil simulasi laboratorium tinggi muka air diatas mercu dengan hasil perhitungan pada mercu ambang lebar dengan variasi debit 1000 1/jam $\left(0,00027 \mathrm{~m}^{3} / \mathrm{det}\right), 20001 / \mathrm{jam}\left(0,00055 \mathrm{~m}^{3} / \mathrm{det}\right), 3000 \mathrm{l} / \mathrm{jam}\left(0,00083 \mathrm{~m}^{3} / \mathrm{det}\right)$ dan debit $40001 / \mathrm{jam}\left(0,0011 \mathrm{~m}^{3} / \mathrm{det}\right)$ dan kemiringan 0 diperlihatkan pada Gambar 7
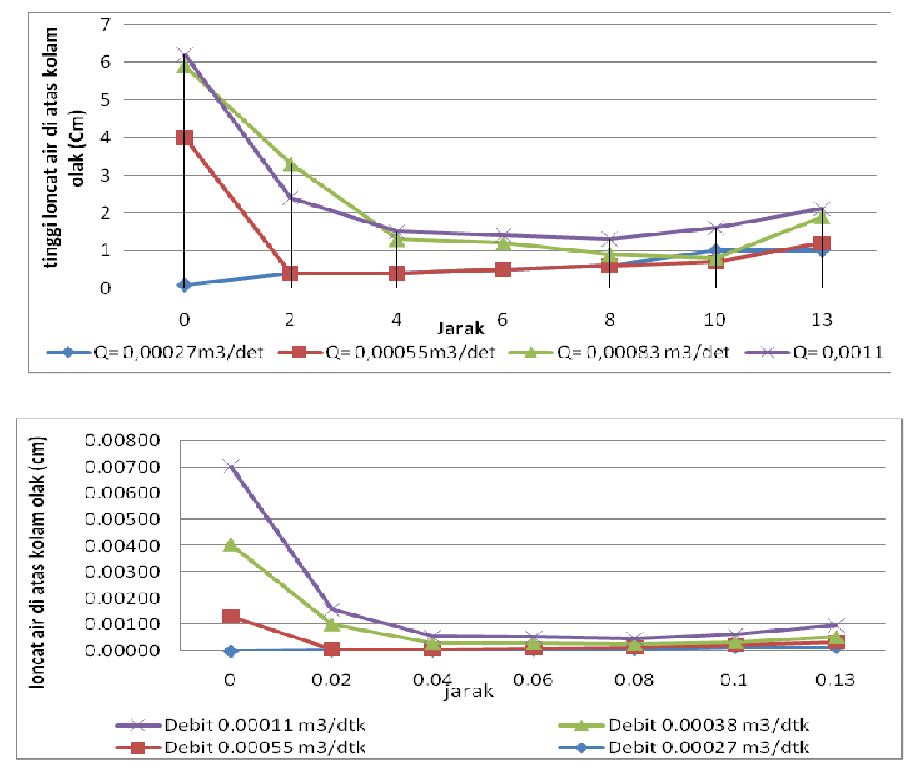

Gambar 7 Grafik Hasil Laboratorium Tinggi Loncat Air di atas Kolam Olak Pada Mercu Ambang Lebar, $\mathrm{S}_{0}=0$

\subsubsection{Gabungan Pada Simulasi Lab Mercu Ambang Lebar Dan Mercu Bulat.}

Untuk melihat hasil dari gabungan simulasi laboratorium pada mercu bulat dan ambang lebar, didapat hasil yang menunjukkan bahwa mercu bulat memiliki hasil loncat air lebih tinggi dibandingkan mercu ambang lebar dengan variasi debit dan kemiringan saluran yang berbeda.

Hasil gabungan dari data simulasi lab pada mercu bulat dan mercu ambang lebar pada $\mathrm{Q}=1000 \mathrm{~L} / \mathrm{Jam}\left(0,00027 \mathrm{~m}^{3} / \mathrm{dtk}\right), \mathrm{Q}=2000 \mathrm{l} / \mathrm{jam}\left(0,00055 \mathrm{~m}^{3} / \mathrm{det}\right)$, $30001 /$ jam $\left(0,00083 \mathrm{~m}^{3} /\right.$ det $)$ dan debit $40001 / \mathrm{jam}\left(0,0011 \mathrm{~m}^{3} / \mathrm{det}\right)$ dan kemiringan 0 dan 2 .

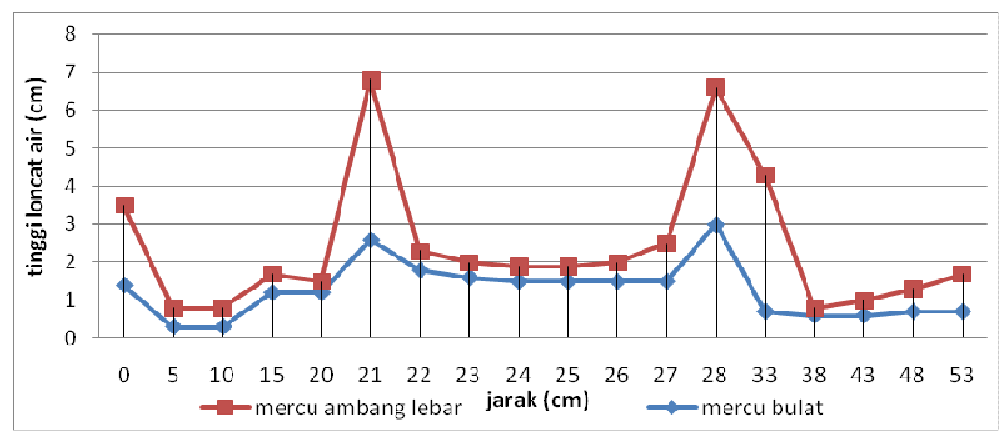

Gambar 8 Grafik Hasil Gabungan Perhitungan Tinggi Loncat Air Kolam Olak Pada Mercu Ambang Lebar Dan Mercu Bulat $Q=0,00027 \mathrm{~m}^{3} / \mathrm{dtk}$ So $=2$ 


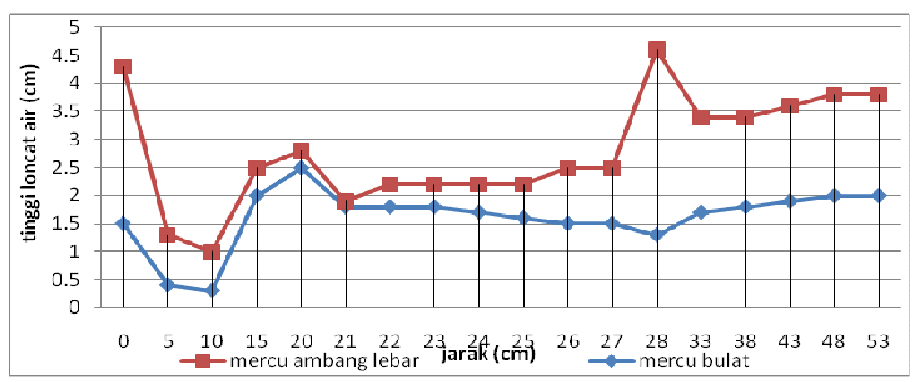

Gambar 9 Grafik Hasil Gabungan Perhitungan Tinggi Loncat Air Kolam Olak Pada Mercu Ambang Lebar Dan Mercu Bulat $\mathrm{Q}=0,00027 \mathrm{~m}^{3} / \mathrm{dtk}$ So $=0$

\section{Kesimpulan}

Dari hasil penelitian dan pembahasan yang telah dilaksanakan, diperoleh kesimpulan sebagai berikut:

1. Besarnya debit, kemiringan dasar saluran dan perbedaan bentuk mercu mempengaruh tinggi loncat air.

2. Semakin besar debit yang dipakai maka semakin tinggi pula loncat air yang dihasilkannya.

3. Tinggi loncat air pada mercu bulat lebih tinggi dari pada tinggi loncat air pada mercu ambang lebar.

4. Kemiringin dasar saluran berpengaruh pada tinggi loncat air yang terjadi pada saat simulasi di laboratorium karena semakin besar kemiringan maka semakin tinggi pula tinggi loncat air yang dihasilkan di hilir bendung.

5. Aliran yang terjadi pada $\mathrm{Q}=1000 \mathrm{l} / \mathrm{jam}, \mathrm{Q}=2000 \mathrm{l} / \mathrm{jam}\left(0,00055 \mathrm{~m}^{3} / \mathrm{dtk}, \mathrm{Q}=\right.$ $3000 \mathrm{l} / \mathrm{jam}$, dan $\mathrm{Q}=4000 \mathrm{l} / \mathrm{jam}$ dan $\mathrm{So}=0,2$ adalah aliran laminer yang alirannya bergerak secara teratur.

6. Tinggi loncat air dikolam olak dipengaruhi oleh bentuk mercu karena terdapat perbedaan. Tinggi loncat air pada mercu bulat dan ambang lebar debit dan kemiringan dasar saluran yang digunakan adalah sama.

\section{Daftar Kepustakaan}

Chow, V. T., 1959, Hidrolika Saluran Terbuka, Erlangga, Jakarta.

Kristanto Yuli, 2011, Kajian Profil Muka Air di Hulu bendung ditinjau Secara Numerik, Jurnal Teknik sipil, http://www.jurnal.com. Diunduh 21 Agustus tahun 2011.

Nastain, Surosa, 2005, Mekanika Fluida, Erlangga, Jakarta

Suripin, 2004, Sistem Drainase Yang Berkelanjutan, ANDI, Yogyakarta.

Triatmodjo Bambang, 1993, Hidraulika II, Beta Offset, Yokyakarta.

Wesli, 2014, Pilihan Teknologi Saluran Simpang Besi Tua-Panglima Kaom

Pada Sistem Drainase Wilayah Iv Kota Lhokseumawe, Teras Jurnal Vol 4 No 1, Jurusan Teknik Sipil Universitas Malikussaleh, Lhokseumawe, hal 0110

Wesli, Said Jalalul Akbar, 2016, Kontribusi Waduk Peudada Terhadap Kebutuhan Air Kabupaten Bireuen, Teras Jurnal Vol 6 No 1, Jurusan Teknik Sipil Universitas Malikussaleh, Lhokseumawe, hal 66-72

Pengaruh Bentuk Mercu Bendung Terhadap Tinggi Loncat Air Kolam Olak Model USBR IV (Simulasi Laboratorium) - M. Kabir Ikhsan 